\title{
CULTURAL "FACES" OF INTERPERSONAL COMMUNICATION IN CHINA AND NIGERIA
}

\author{
Alexander O. Anedo \\ doi: $\underline{\text { http://dx.doi.org/10.4314/og.v8i1.12 }}$
}

\section{Introduction}

Assuming that interpersonal communication is a "deeply cultured process," (Philipsen, 1992) this essay illuminates the different ways interpersonal communication is conceptualized in Nigeria and China through reviewing studies of one core symbol - face - in the two cultures. It demonstrates that embedded in the face concept are culture-specific notions of personhood that give rise to culture specific models of interpersonal communication: the individual based, self-oriented, and rational Nigerian face is enacted through an "information game" model of social interaction whereas the relationbased, other-directed, and emotional Chinese face is performed via a "relationship game" model of interpersonal communication.

A call for more empirical research of Chinese interpersonal communication from a cultural perspective is also made. This paper discovered that over the past several decades, communication studies scholars have called for attention to the "culturally constituted" nature of interpersonal communication (e.g., Car Baugh, 1988, 1990; Fitch, 1998; Leeds-Hurwitz, 1995; Philipsen, 1992; Stewart, 2002). In the introduction to their newly edited book, A Cultural Approach to Interpersonal Communication, Monaghan and Goodman (2006) challenged readers to question and "denaturalize" what have normally been taken-for-granted communicative practices. They alerted that "the ways people interact with others are linked to larger cultural understandings and expectations" and thus communication should be viewed "in terms of shared cultural knowledge that is learned and practiced" (p. 1). What this implies is that culture is constituted and created in interpersonal communication processes in which people use linguistic and nonlinguistic symbols to negotiate and construct shared meanings in patterned ways.

Core symbols are rich sources of cultures (Collier, 1988; Schneider, 1968). Collier (1988) rightly claimed that "core symbols can be differentiated from one another on a variety of dimensions 
and can be used to compare and contrast cultures" (104). This paper is going to describe the different notions of one core symbol - face - in the Nigerian and Chinese culture through reviewing scholarly writings and research on the symbol. Such a comparative study will illuminate the different ways interpersonal communication is conceptualized in Nigeria and China. It will demonstrate that embedded in the face concept are culture-specific notions of personhood, relationships, and strategic actions that give rise to culture-specific models of interpersonal communication: the individual based, self-oriented, and rational Nigerian face is enacted through an "information game" model of social interaction whereas the relation-based, other-directed, and emotional Chinese face is performed via a "relationship game" model of interpersonal communication. A call for more empirical research of Chinese interpersonal communication from a cultural perspective is also made.

\section{Face in Nigeria and China}

Though face phenomenon was claimed to be universal by Goffman (1967) and Brown and Levinson (1978/87), its social meanings and functions are culturally constituted. This study is going to compare Nigerian face as it is mainly defined by Goffman (1967) and Brown and Levinson (1978/87) and Chinese face, which will illuminate culture-specific notions of personhood, social relationships, and strategic communication. Goffman (1967) defined face as "the positive social value a person effectively claims for himself [sic] by the line others assume he $[$ sic] has taken during a particular contact" (p. 5). In this definition, face is the individual consciousness of his or her public image. As Ho (1994) rightly contended, in the Western cultures, gaining face or winning approval is the most important social motive for individuals. In order to establish this positive image, the person has to talk, behave, and act in ways that should be consistent with his or her expected self-image, for otherwise he or she will be "in wrong face" or "out of face." Goffman (1967) uses face-work to describe a person's self-conscious efforts to build a positive image. The whole process, including motives, preparations, and public performances, which are all under the individual's conscious control, is "impression management." "A self expressed 
through face" captures the very individualistic nature of Goffman's notion of "face." Face captures individualized identities and everybody has a unique and self defined face through strategic and tactful performance of self in others' presence. This is why the Igbo of Nigeria normally say, "Ihu di mma adighi mma ikpe mbo." (Nice face is never good for pinching). Literarily, nice face should be devoid of any form of wound; otherwise, the face ceases to look good. However, it means that good relation should be maintained by avoiding ugly tendencies. Social order hinges upon individuals' face-work - out of the "face" need, individuals discipline themselves - and therefore, society exists as a consequence of each individual's self regulation. Being rational becomes a crucial feature of Nigerian face. As Goffman (1967) asserted, a person who is conscious of his or her face (i.e., the social front or public face) is rational and calculated: "When an individual enters the presence of others, they commonly seek to acquire information about him [sic] or to bring into play information about him [sic] already possessed" (Goffman, 1969, p. 9). Such a person is strategic and purposeful when he or she interacts with others in getting and sending off information in order to impress others positively. When everyone in a society is rational and calculated in their actions, they are able to respect each other's faces: a person's performance of face-work, extended by his tacit agreement to help others perform theirs, represents his willingness to abide by the ground rules of social interaction. Here is the hallmark of his [sic] socialization as an interactant. If he $[\mathrm{sic}]$ and the others were not socialized in this way, interaction in most societies and most situations would be a much hazardous thing for feelings and faces." (Goffman, 1967, p. 31). Thus, a fair and equal transaction is a precondition for the existence of the individualistic face. A person should act in ways that help build his or her own public image, but allow him or her to respect others' need for positive images:

Information about the individual helps to define the situation, enabling others to know in advance what he [sic] will expect of them and what they may expect of him [sic]. Informed in these ways, the others will know how best to act in order to call forth a desirable response from him [sic] (Goffman, 1959, p. 1). The conscious individual controls information issuance-he or she decides what to 
send and what to withhold in accordance with the principle of face defense and face protection. The successful control by the individual will, on the one hand, maintain, repair, and define the situation, and on the other hand, demonstrate his or her competence as an interactant. To summarize, Goffman's face is self-oriented, individual-based and rational, and it functions as a transactional symbol that regulates social interactions and helps create social order. Goffman claims that members of every social circle should have some knowledge of face-work and some experience in its use. In Igbo (Nigerian) society, it is a type of savoir-faire, tact, or diplomacy. This social capacity resides in the very social skill of modifying, either prescriptively or proscriptively, all acts with a consideration of face.

Embedded in such a face concept are cultural beliefs that a person is an independent, self-reliant, and self-oriented being (Car Baugh, 1988; Hsu, 1973) who tactfully interacts with others as unique and self-contained individuals (Brown \& Levinson, 1978, 1987). Interpersonal communication in the Igbo (Nigerian) culture puts into daily practice such notions of individualistic face and all the cultural premises about personhood that it entails.

\section{Chinese Face}

The face concept has been identified by many scholars as one of the core symbols in the Chinese culture (Chang \& Holt, 1994; Cheng, 1986; Ho, 1976, 1994; Hu, 1944; Hwang, 1987, 2000; Jia, 1997; Scollon \& Scollon, 1994). Scholars who examine face in the Chinese culture are quick to critique the highly individualistic face depicted by Goffman (1967) and Brown and Levinson (1978/87). They contend that in Chinese culture, there is no unique or individualized face or self. Ho (1994) suggested that to study Chinese face, we cannot use individuals as the unit of analysis; instead, we should examine individuals-in-relations. His notion of relationalism was echoed by other scholars (e.g., Chang \& Holt, 1994; Hwang, 1976, 2000). In Chinese society, a person is so caught up in a network of relationships that he or she does not have a unique face; rather, it is shared by others in the relational network. Hence, it is communal. Ho (1994) argued that Chinese face is a field concept: It [face as a field concept] takes full recognition of the individuals' embeddings 
in the social network. A methodological consequence is that the analysis of face behaviour, even when pertaining to a single individual, must extend its domain to include: a) actions by the individual, either self-initiated or in response to those of others; b) actions by other people closely associated with the individual; c) actions directed at the individual by people with whom the individual is interacting; d) actions directed at the individual by people closely associated with those with whom the individual is interacting; and finally, e) actions directed at people closely associated with the individual by those with whom the individual is interacting directly or indirectly (Ho, 1994, p. 271).

As a field concept, Chinese face is not an individual's "thing." Consequently, unlike its Nigerian counterpart, it may be beyond an individual's control. Not only one's own actions affect one's face, but others in the social network may affect one's face through their actions for which the individual may have no responsibility. Chang and Holt (1994) argued that Chinese face is rooted in relations (Kuan-hsi) so that face is shared by people in relationships: "Mien$t z u$ (face) can be claimed not only by individuals, but can also be shared by members of the in-group, or by people in specific social situations" (Chang \& Holt, 1994, p. 101). What this amounts to is that Chinese face can be communally created and owned. One may claim face or lose face as a result of others who are related in some way. One recent news story from Yang Cheng Evening News (March $30,2007)$ brings home this communal nature of Chinese face. The story describes one man's experience over a period of more than a decade. He grew up in rural China, but through his hard work and intelligence, he was admitted into Qinghua University, one of the top universities in China. His success - being also the first one in his village who was admitted to Qinghua University - brought honor or face to his parents and people living in the same village. However, 10 years later, he was selling noodles in his hometown as a way of living; he was not able to get a decent job in Beijing or other big cities, and this was considered dishonorable. His parents felt ashamed (lianshang wu guang) by his conduct and became even reluctant to mention his name to others. Thus, this man's loss of face was shared by his parents and others related to him. His face became communal. 
Closely linked to the communal feature of Chinese face is the fact that it is morally defined. Hu (1944) distinguished lian and mianzi, which in Chinese language both refer to face; lian is something that "represents the confidence of society in the integrity of [the] ego's moral character, the loss of which makes it impossible for him or her to function properly within the community" (p. 45). To put it simply, lian represents the moral values of a person in the Chinese society. Mian and mianzi, on the other hand, "stand for the kind of prestige that is emphasized in [Nigeria]: A reputation achieved through getting on in life, through success and ostentation" (Hu, 1944, p. 45). Similarly, King and Myers (1977) defined lian as "a moral face" and mianzi as "a social or positional face." Gao and Ting-Toomey (1998) further explicated the meanings of lian and mianzi, arguing that lian embodies a moral dimension and is often "internalized"; whereas mianzi represents a social image and is often "externalized." Cheng (1986, p. 326) defines mianzi and lian in terms of "two limits of human dignity, social acceptability or social respectability of a person in a society" — mianzi represents "the uppermost limit of one's dignity and social respectability," whereas lian represents "the lowest limit of such." Scholars generally agree that mianzi is more equivalent to American face (which could also apply to Nigerian situation), though they are not the same (Ho, 1976; $\mathrm{Hu}, 1944)$.

However, lian is a concept that is peculiar to the Chinese culture, and it enacts Chinese cultural values of morality as an important criterion for being a competent person that is grounded in the philosophical ideologies of Confucianism (Chang \& Holt, 1994; Cheng, 1986; Jia, 1997). Like mianzi, lian can also be shared, thus communal. A criminal does not have lian (Ho, 1994) as a result of his or her conduct that takes away the society's confidence in "the integrity of [the] ego's moral character" and "makes it impossible for him or her to function properly within the community." To a greater or lesser degree, the criminal's family members, friends, or neighbours also have their lian lost due to the criminal's conduct. This is captured by the Chinese expression, wuyan or meilian (having no face). For example, the criminal may meilian (have no face) to see his or her relatives because he or she has lost their lian. From this moral sense of Chinese face, we can see the coercive or 
normative function of face in Chinese society in regulating individuals' behaviours since a person is not only responsible for his or her own face but others in the social network (Ho, 1994; Hu, 1944). Finally, closely linked to mianzi is renqing (human feelings), that is, the emotional dimension of Chinese face. Mianzi and renqing go hand in hand and mutually influence each other in Chinese culture (i.e., the increase in one correlates to an increase in the other, and vice versa).

A person may claim favor (or mianzi) on the basis of the amount of renqing that exists in proportion to the type of relationship between him/her and the other (Hwang, 1976). Relationships are not equal; rather, they are hierarchically defined on the basis of the amount of mianzi and renqing. When A does a favor to $\mathrm{B}$, which means that $\mathrm{A}$ gives $\mathrm{B}$ mianzi, $\mathrm{B}$ owes renqing to $\mathrm{A}$ and is expected to return the renqing to $\mathrm{A}$ in the future (i.e., reciprocity or bao) (Chang \& Holt, 1994; Hwang, 1976). If B cannot return the renqing to $\mathrm{A}, \mathrm{B}$ loses mianzi to $\mathrm{A}$. Such social interaction that is built on mianzi and renqing became the controversial theme of a new Chinese TV series entitled The New Marriage Time (2006). This series focuses on all the issues and problems that originate from a marriage between a city wife and her countryside husband. The husband's father reasons that since his son is married to the woman, she and her distinguished parents should give him the mianzi and renqing by helping him. The father assumes that given her family's high social status, they have a lot of mianzi and renqing with others in powerful positions. In one episode, for instance, the father asks the wife's mother, who is a famous doctor, to examine a friend from his village without having to follow the normal procedures. The father also asks the wife's family to find a job for the husband's older brother in the city. Eventually, too many conflicts and disputes arise due to the incessant request for mianzi and renqing. Ultimately, these conflicts result in the couple's divorce. One question that was invoked repeatedly throughout the show is, when one marries someone, does he/she also marry his/her family and all other social relationships? This is actually a questioning of the practice of mianzi and renqing in Chinese society. To summarize, Chinese face is different from Nigerian face in that it is other-directed rather than self-oriented (Ho, 1976, 1994; Hwang, 1976, 2000; Jia, 1997). It is 
communal or relational rather than individualistic; it is emotionally based (Chang \& Holt, 1994; Hu, 1944) rather than rational; and, it is moral (Cheng, 1986; Ho, 1976; Hu, 1944; Jia, 1997) rather than transactional or amoral. Deeply rooted in the Chinese concept of face are conceptualizations of a competent person in Chinese society: one who defines and puts self in relation to others and who cultivates morality so that his or her conduct will not lose others' face. This contrasts with the Nigerian cultural definition of a person who is expected to be independent, self-reliant, and successful. The end result is that a Chinese person is expected to be relationally or communally conscious whereas an Nigerian person is expected to be self-conscious. The different notions of personhood as enacted by the contrasting face concepts are reflected through and shape different patterns of interpersonal communication in the two cultures.

\section{Interpersonal Communication in Nigeria \& China}

As interpersonal communication involves two persons, how a person is culturally defined both influences and is enacted through the communication process. Interpersonal communication in Nigeria and China is each influenced by and enacts cultural conceptualizations of personhood as rooted in the face concepts in the two cultures respectively.

\section{Interpersonal Communication as an "Informational Game": The Nigerian Model}

Goffman (1959) described social interaction as a process of "reciprocal influence of individuals upon one another's actions when in one another's immediate physical presence" (p. 15). The individuals involved in a social interaction are unique and independent. One is the performer or participant and the other is the "audience," "observer," or "co-participants" who "contribute to the other's performances." Sending and receiving information (i.e., message construction and self disclosure) constitutes the central purpose of social interaction. Rational and goal-oriented, competent communicators know what information to disclose about themselves and what information to obtain from others, which Goffman (1959) called an "information game": This kind of control upon the part of 
the individual reinstates the symmetry of the communication process, and sets the stage for a kind of information game-a potentially infinite cycle of concealment, discovery, false revelation, and rediscovery. (Goffman, 1959, p. 8) An individual utilizes two channels to send and obtain information: Verbal and nonverbal. Verbal assertions are the part of information that is normally within the individual's conscious manipulation, while nonverbal "givenoffs" are chiefly ungovernable. The others, knowing that the individual is likely to present himself or herself in a favorable light, will divide what they see into two parts-the governable and the ungovernable - and use the latter as a check upon the validity of the former. Interpersonal communication in Nigeria is, thus, individualbased and self-oriented. It is a symbolic process through which individuals use verbal and nonverbal means to influence others to benefit themselves personally and professionally. This information game is governed and regulated by norms or rules of interaction that are derived from basic face wants shared by all (Brown \& Levinson, 1978, 1987). All individuals, according to Brown and Levinson, have the need for positive face-the need to be respected and recognized-and negative face-the need for freedom of action and speech. Permeated in social interactions are potential face threatening acts (FTA) such as making requests, asking questions, criticizing, praising, issuing orders, and so on, which are essential means to exude, transmit, and acquire information between participants (Brown \& Levinson, 1978, 1987; Tracy, 2002). To protect, defend, and avoid communication breakdowns, individuals should use politeness strategies to reduce or eliminate the threat of FTA. The politeness-regulated social interaction invokes the individualistic face concept; each individual's face is equal to everybody else's and deserves respect from others. In this rational and mechanical process of interpersonal communication, norms or rules of interaction apply to all individuals. To put it in Goffman's terms (1959), for social interaction to happen smoothly, every individual needs to perform by following a "part" or "routine" that is a "pre-established pattern of action which is unfolded during a performance and which may be presented or played through on other occasions." That all individuals' faces are equal to each other stipulates that everyone has the right to express his or her self and no 
one else should impose his or her personal views onto others (Car Baugh, 1988; Katriel \& Philipsen, 1981).

Face is the symbolic token by which all information is censored: In any society, whenever the physical possibility of spoken interaction arises, it seems that a system of practices, conventions, and procedural rules comes into play which functions as a means of guiding and organizing the flow of messages. (Goffman, 1967, pp. 33-34). To summarize the model of interpersonal communication that is embedded in the Nigerian face concept: an individual enters the physical presence of others, and this signals to the person to put on his or public "face" or "social front." Then the person starts sending information about him or herself to others, both verbally (the given) and nonverbally (the given-off). The others receive the information and evaluate it by checking the validity of the verbal information against the nonverbal information. The individual's consideration of "face" of both self's and other(s)' regulates and organizes the flow of messages. Interpersonal communication, thus, is an information game between two independent individuals, the successful play of which depends on the rational, self-conscious, and tactful manipulation of each other's face verbally and nonverbally. Such a model is reflected by the contents of most interpersonal communication textbooks (e.g., Adler, Rosenfeld, \& Proctor, 2006; DeVito, 2005), which emphasize self concept and impression management, perception, listening, emotional communication, self disclosure, verbal and nonverbal expressions in general and in various settings - workplace, family, public, close relationships, conflicts, and computer-mediated interactions. Knowledge of and skills in effective use of verbal and nonverbal expressions (i.e., sending and perceiving information) in various contexts, thus, constitutes one major goal of interpersonal communication. Even when relationships are studied, the focus is mostly on how an individual manages verbal and nonverbal messages to create, maintain, or terminate relationships. To put it another way, relationships are mostly treated as the contexts in which individuals send, receive, and process verbal and nonverbal messages to benefit self the most. Interestingly, there have been scholars in Africa who, against the predominant focus on information exchange in the interpersonal communication field, 
suggested that the interdependency between human beings should be emphasized in the African culture. Hence, they advocate a more relational model of interpersonal communication in Africa (e.g., Carl \& Duck, 2004; Stewart, 2002). In contrast to the information game model of interpersonal communication, social interactions in China take on quite different patterns. For the sake of contrast, the study will characterize the Chinese interpersonal communication as a "relationship game."

\section{Interpersonal Communication as a "Relationship Game": The Chinese Model}

Unlike Nigeria face, Chinese face, as discussed above, is relationally based, other directed, and morally-laden. Individuals are not unique and independent as they are expected in Nigeria; rather, they find themselves in various social networks. They need to be cautious with what they say or do since their action will affect others in the relationships. What is more, the button of information control, to use Goffman's term, is not held completely in a person's hands since other people's actions may affect one's face beyond one's control. Therefore, the rational and mechanical model of social interaction cannot be applied to the Chinese cultural context. To understand interpersonal communication in China, we need to focus on the emotional, relational, and particularistic (Chang \& Holt, 1994; Hwang, 1987; Yum, 1988), which evokes hierarchy and power. That is to say, interpersonal communication in China follows situationoriented patterns (Hsu, 1973), which are defined by different relationships (guanxi), emotions (renqing), and face (mianzi).

Relationships are the foundation for social interaction in the Chinese society. Instead of talking about relationships in general, Hwang (1987) classified three sorts of interpersonal relationships in China, each of which calls for quite different patterns of interaction. The first type of interpersonal relationship is characterized with an "expressive tie." Hwang (1987, p. 949) defined the expressive tie: [It is] generally a relative permanent and stable social relationship. It can render an individual's feelings of affection, warmth, safety, and attachment. This kind of tie occurs mostly among members of such primary groups as family, close friends, and other congenial groups. Aside from the satisfaction of affective feelings, one can, of course, 
utilize this tie as an instrument to procure some desired material resource, but its expressive component always claims precedence over its instrumental component. The family relationship is considered the most important one in the Chinese society, influenced by Confucian philosophical ideologies (Chang \& Holt, 1994; Cheng, 1986; Hsu, 1973; Hwang, 1987). Hwang (1987) points out, "A typical Chinese family usually encompasses the multiple functions of economy, religion, education, and recreation, so that it can meet most of an individual's needs" (p. 949-950). The second type of interpersonal relationship is defined by an "instrumental tie":

With a view of attaining his [sic] material goals, an individual must establish instrumental ties with other people outside his family in his daily life. When an individual attempts to establish an expressive tie with other people, the tie is the goal in itself. But when one attempts to establish an instrumental tie, the relationship serves only as a means or an instrument to attain other goals. Thus, this relationship is basically unstable and temporary. This latter relationship exists, for example, between salesmen [sic] and customers, bus drivers and passengers, nurses and outpatients in a hospital, and so forth. (Hwang, 1987, p. 950) According to Hwang (1987), people adopt a universal principle, instead of a personal one, when they interact with strangers (i.e., instrumental ties). The social exchange theory applies to interaction between Chinese in the instrumental ties. He cited empirical evidence to indicate that Chinese people tend to behave rationally when interacting with strangers. For example, Chinese people tend to discourage and inhibit aggressive outbursts in order to maintain interpersonal harmony within their group. But "collective acts of aggression toward a stigmatized out group might be drastic and even exaggerated for the sake of group serving" (Hwang, 1987, p. 952). The reason, he explained, lies in the fact that "one's need for social affiliations is fully satisfied within already established groups" (Hwang, 1987, p. 951). The third type of interpersonal relationship is characterized with a "mixed tie," defined by Hwang (1987, p. 952) as: [It] is a relationship in which an individual seeks to influence other people by means of renqing and mianzi. Both sides of a mixed tie know each other and keep a certain expressive component in their relationship, but it is never so strong that all participants in this tie 
could express their authentic behaviour as freely as can the members in the expressive tie. This kind of relationship, which has been termed a particularistic tie, occurs chiefly among relatives, neighbours, classmates, colleagues, teachers and students, people sharing a natal area, and so forth.

Since each person is involved in series of such mixed ties, “... the overlapping and interacting of these reticular result in an extremely complicated network of social relations" (Hwang, 1987, p. 952). Thus, the third type of interpersonal relationships constitutes the biggest and most complicated social networks (i.e., guanxi). Interaction between people in the mixed tie is influenced by considerations of human feeling (renqing) and face (mianzi), rendering it an emotional, relation-based, and particularistic process. Human feelings (renqing) can be used as a resource to be presented to another as a gift in the form of money, goods, or service. Not only can it be material goods, but it can be abstract in the form of affection. Most importantly, it is "a set of social norms by which one has to abide in order to get along well with other people in Chinese society" (Hwang, 1987, p. 954). Stipulated by the rule of renqing are two behavioral patterns: Ordinarily, one should keep in contact with the acquaintances in one's social network, exchanging gifts, greetings, or visitations with them from time to time, and 2). When a member of one's reticulum gets into trouble or faces a difficult situation, one should sympathize, offer help, and "do a renqing" for that person. (Hwang, 1987, p. 954) Hence, interpersonal interaction possesses different patterns in the three types of relationships. Among people in the expressive tie, they are bound by blood tie (i.e., consanguine relationships) and obligations. For example, a mother is obligated to take care of her children and discipline them when they are little. Children are obligated to look after their parents when they get old. Since such ties are permanent and stable, all the obligations and responsibilities that connect people together are also permanent and unchanging (Hsu, 1973). Hsu argued that because of the permanent nature of the relationship in a family, Chinese people feel more security than their counterparts in the western world. This paper has to confirm Chinese case here as happening in Nigeria and the rest of Africans. 
There has been limited empirical research on communication patterns in contemporary Chinese families. Zhong, Myers, and Buerkel (2004) used the self report method to explore whether there are any differences between fathers and their adolescent sons in terms of self disclosure, empathy, and homophily (i.e., the perception of similarity between two people). They found that fathers seemed to have more intent to disclose than sons; they were more willing to respond and show empathy; but they also reported a lower level of homophily than their sons. Their findings indicate some change in the relationship between fathers and sons in Chinese families from the traditional Confucian pattern in that fathers seem not to perceive themselves as the unquestioned authority figures in front of their sons any more; rather they show more interest in understanding their children and opening themselves up to their children.

An explorative study by Zhang (2007) revealed a somewhat similar trend in Chinese families. Also using self-report method, Zhang found that contemporary Chinese family communications were more conversation-oriented than conformity-oriented, the latter being a characteristic of traditional Chinese families. The conversation-orientation values diversity of views and independence among family members: Conversation orientation is the degree to which a family stresses the heterogeneity and diversity of ideas, attitudes, and beliefs; thus, a conversation-oriented family values the individuality and independence of family members and spontaneous and unconstrained interactions. (Zhang, 2007, p. 114) Through a close examination of one daily conversation between a grandmother and her teenage grandson in one Chinese family, Chang (2007) demonstrated how traditional Chinese cultural values represented by the grandmother's voice clash with modern values represented by her grandson's voice in daily social interactions. Among people in instrumental ties, interactions are mostly impersonal and universal (Gao \& Ting-Toomey, 1998). People interact for purposes of achieving goals. They do not expect to carry on the relationship after the business is done.

Finally, among people in mixed ties, interactions are personal and particularistic. There is a certain element of obligation, but it is not as strong as in expressive ties. The obligation revolves around 
the reciprocation (bao) of renqing and mianzi, as discussed earlier in the paper. The different types of relational contexts give rise to different attitudes, feelings, and behaviour among Chinese people. For a Chinese person to survive, it is not so much a matter of mastering verbal and nonverbal skills to transmit and acquire necessary information, but instead, it is a matter of mastering the techniques of managing social relationships through the manipulation of such core symbolic tokens as renqing, guanxi, and mianzi. According to Cheng (1986), this requires the moral selfcultivation situated in social relationships and the larger sociopolitical environment: First, self-cultivation of a person must be conducted in the context of developing social relationships. Second, the successfulness of self-cultivation of a person must be judged in terms of successfulness of development of social relationships under a rule of government. Third, the ultimate form of successfulness of development of social relationships is a good government under which everyone is well and properly placed in an order of social relationships and everyone will look upon the maintenance and improvement of this order as defining an intrinsic quality of his [sic] existence as well as the worth of his moral achievement. (pp. 337338).

Developing and maintaining social relationships is thus the measure of a person's moral development and success. A person is caught in a set of Guanxi wang (relational networks) (Chang \& Holt, 1994) so that his or her action is fateful, to use Goffman's term, in that it produces consequences that impact his or her self development in a society, and more importantly, his or her social life. The various roles that a Chinese individual plays are so important that Ge and Ting-Toomey (1998, p. 18) claim that "the role, not the self, determines the behaviour."

Also implied is the hierarchical nature of social relationships. Scholars have noted that due to the hierarchy of social relationships, renqing and mianzi are also quantifiable in terms of size and degree (Ho, 1994; Hwang, 1987). That is to say, renqing and mianzi are not equally distributed; rather, they vary as a result of personal moralcultivation, status, profession, wealth, and so on.

Renqing, mianzi, and guanxi are useful tools to exercise social influence and control in Chinese society (Chang \& Holt, 1994; Ho, 
1976, 1994; Ma, 1992). They can be "borrowed, struggled for, added, or padded-all terms indicating a gradual increase in volume" (Hu, 1944, p. 61). A, who has mianzi or renqing with B, will not refuse B a favor. Once A does B a favor by increasing B's prestige in front of other people, he [she] is said to give mianzi. As a result, $\mathrm{B}$ is indebted to $\mathrm{A}$ for mianzi and renqing. To follow the reciprocity principle, B should later try to return A a mianzi and renqing. Also, one can also borrow someone's mianzi, meaning that one can take advantage of one's acquaintance with a person of prestige in the community. This can be one of the reasons why Chinese never leg a foreigner go without posing for photograph with him or her. This is a kind of ego boasting as it indicates one's high status having foreign friends.

This latter happens when dealing with interpersonal conflicts among Chinese (Jia, 1997; Ma, 1992; Ting-Toomey, 1985; TingToomey \& Oetzel, 2002). This study discovered that Ma (1992) interviewed 25 Chinese in a large city in Central China and found that unofficial intermediaries were pervasively used as a strategy for resolving interpersonal conflicts. The intermediary was not selected by either party involved in a conflict; rather, people mediated without being invited or after being invited by a third party. Only insiders can function as intermediaries. The use of intermediaries allows Chinese people to resolve conflicts through nonconfrontational means, protecting both parties' face. Impartiality and face maintenance were two key elements for successful mediations. After analyzing a transcribed set of interactions at a seminar among three Chinese guest professors, the chair of the department at a U.S. university (also Chinese), and Chinese students, Jia (1997) concluded that face-work was used as a conflict-preventive mechanism among them. His analysis focused on the subtle yet powerful functions of face maintenance, face redress, self effacement, and face enhancement in regulating the social interactions as well as the social relationships among the participants. He showed that the notion of hierarchy was deeply embedded in the Chinese face concept, and it was enacted through patterns of naming (see also Cheng, 1986); face redressing behaviour, and long silences. He also found that face-work discourse was characterized by other-directed face, self-trivialization, and 
attempts to redress face threat. He claimed that when these patterns of discourse were used appropriately, they helped prevent relational conflicts and maintain harmony.

The use of unofficial intermediaries and face-work discourse as conflict management and prevention methods challenge the western perspective of conflict management and resolution that are individual-based and self-oriented. Jia (1997) stated, "As the Chinese framework of face suggests, the view that actively invoking conflicts and putting them under rational control with the belief that conflicts are natural and can be healthy and constructive runs counter to the fundamental Chinese notion of social harmony." Scollon and Scollon (1994), after examining the different positioning of face-work in interpersonal interactions in the east and the west, found that there was a "relative difference in their assumptions about the first task to be dealt with in their exchange" (Scollon \& Scollon, 1994, p. 136). The east follows what they termed a "centrist" pattern in initial conversations, starting with face-work, followed by business or topic, and closing with facework. The west follows the pattern of topic, face-work and reiteration of topic. Such a different sequential pattern of conversations reveals relatively different emphasis on information exchange for westerners and on relationship for easterners in talking. They traced the source of such differences to the cultural concepts of face in the west and east: Self in the eastern culture is relationalintimate relationships are within the boundaries of self, namely, self is defined by close relationships. In contrast, self in the west is bounded and unique, untangled or uninfluenced by others including family, pets, or anything else (Hsu, 1973). Mianzi and its associated symbols - renqing and guanxi - are tokens of social power in China. They can be social lubricants or sources for interpersonal effectiveness. For example, they can be effectively used by individuals to achieve goals (e.g., finding a job or getting one's child into a better school). They can be used to resolve interpersonal conflicts. Just as much as they are powerful lubricants, they can be significant barriers to interpersonal communication, too. For example, people who do not possess enough mianzi, renqi, or guanxi may find it difficult to accomplish anything. In social interaction, because of the concern for mianzi, people may refuse to apologize or 
admit mistakes, which may cause tension or estranged relationships (Chang \& Holt, 1994)

In sum, interpersonal communication in the Chinese cultural context is driven by face (mianzi), human feelings (renqing), and social relationships (guanxi). Discourse and meta-discourse about the core symbol of face and its related symbols render interpersonal communication a symbolic process of power or relational games, the successful play of which depends on the appropriate utilization and reciprocation of mianzi, renqing, and guanxi. As a result, interpersonal communication in Chinese society is emotionally based, relationally oriented, and morally laden.

\section{Conclusion}

So far, this study has compared and contrasted one core symbol face - in Nigeria and China. While Nigerian face is individualbased, rational, and self-oriented, Chinese face is relational/communal-based, emotional, and other-directed. Embedded in the individual-based Nigerian face are cultural definitions of a person as unique, independent, and self-reliant. Embedded in the relational-based Chinese face are beliefs that individuals are caught in relationships in which moral conduct is essential for self and others. The different notions of personhood influence and are enacted through different models of interpersonal communication in the two cultures. Characterizing interpersonal communication in Nigeria is an "information game" in which individuals as independent parties seek, transmit, and obtain information for self benefit through the appropriate use of verbal and nonverbal means. But interpersonal communication in the Chinese culture is a "relationship game" in which people who are entangled in various social networks utilize and reciprocate core symbols such as mianzi, renqing, and guanxi to achieve their goals. While the information game is characterized with rationality and universal rules, the relationship game is characterized with emotionality and particularistic rules. More empirical research of interpersonal communication in contemporary Chinese society is needed. Existing empirical studies have mostly used survey or self-report methods. Future research may also take what Monaghan and Goodman (2006) proposed a cultural approach, which is comparative, ethnographic, 
and performance-based. Such an approach focuses on describing and interpreting communicative practices as ongoing processes from the participants' or the insiders' perspectives. Taking a cultural approach, researchers may conduct participant and or nonparticipant observations of naturally occurring interactions among Chinese people in specific contexts and try to understand them from the natives' perspective. 


\section{References}

Adler, R. B., Rosenfeld, L. B., \& Proctor, R. F. (2006). Interplay:

The Process of Interpersonal Communication. USA: Oxford University Press.

Brown, R., \& Levinson, L. (1978/87). Politeness: Some Universals in Language use. New York: Cambridge University Press.

Carbaugh, D. (1988). Talking American: Cultural Discourses on Donahue. Norwood, NJ: Ablex.

Carbaugh, D. (1990). Cultural Communication and Intercultural Contact. Hillsdale, NJ: Lawrence Erlbaum Associates.

Carl, W. J., \& Duck, S. W. (2004). How to do Things with Relationships... and How Relationships do Things with Us. In P. Kalbfleisch (Ed.), Communication Yearbook, (Vol. 28, pp. 1-34). Mahwah, NJ: Lawrence Erlbaum Associates.

Chang, H. C., \& Holt, R. (1994). A Chinese Perspective on Face as Inter-relational concern. In S. Ting-Toomey (Ed.), The Challenge of Facework: Cross-cultural and Interpersonal Issues (pp. 95-132). Albany, NY: SUNY Press.

Chang, Y. (2007). Multiple Voices of Culture in Conversation. Paper Presented at the Annual Conference of the International Communication Association. San Francisco, CA.

Cheng, C. Y. (1986). The Concept of Face and its Confucian Roots. Journal of Chinese Philosophy, 13, 329-348.

Collier, M. J., \& Thomas M. (1988). Cultural Identity: An Interpretive Perspective. In Y. Y. Kim \& W. B. Gudykunst (Eds.), Theories in Intercultural Communication (pp. 99- 120). Newbury Park, CA: Sage.

DeVito, J. (2005). The interpersonal communication book (10th ed.). Needham Heights, MA: Allyn and Bacon.

Fitch, K. (1998). Speaking relationally: Culture, communication and Interpersonal connections. New York: Guilford Press.

Geertz, C. (1973). The Interpretation of Culture: Selected Essays. Basic Books.

Gao, G., \& Ting-Toomey, S. (1998). Communicating Effectively with the Chinese. ThousandOaks, California: Sage.

Goffman, E. (1959). The Presentation of Self in Everyday Life. New York: Doubleday. 
Goffman, E. (1967). Interaction Ritual. Chicago, IL: Aldine Publishing Company.

Goffman, E. (1963). Behavior in Public Places. NY: The Free Press. Goffman, E. (1969). Strategic Interaction. Philadelphia, PA: University of Pennsylvania Press.

Goodman, J. E., \& Monaghan, L. (2006), Introduction. In L. Monaghan, \& J. E. Goodman (Eds.), A Cultural Approach to Interpersonal Communication: Essential Readings (pp.1-5). Malden, MA: Blackwell Publishing.

Ho, D. Y. (1976). On the Concept of Face. American Journal of Sociology, 81(4), 867-884.

Ho, D. Y. (1994). Face Dynamics: From Conceptualization to Measurement. In S. Ting-Toomey (Ed.), The Challenge of Facework: Cross-cultural and Interpersonal Issues (pp. 269-286). Albany, NY: SUNY.

Hsu, F. (1973). Americans and Chinese: Purpose and Fulfillment in Great Civilizations. Garden City: Doubleday Natural History Press.

$\mathrm{Hu}$, H. C. (1944). The Chinese Concept of "Face". American Anthropology, 46, 45-64.

Hwang, K. K. (1987). Face and favor: The Chinese Power Game. American Journal of Sociology, 92(4), 944-974.

Hwang, K. K. (2000). Chinese Relationalism: Theoretical Construction and Methodological consideration. Journal for the Theory of Social Behavior, 30(2), 155-178.

Jia, W. (1997). Facework as a Chinese Conflict-preventive Mechanism-A Cultural Discourse Analysis. Intercultural Communication Studies, 7(1).

Katriel, T., \& Philipsen, G. (1981). "What We Need is Communication": "Communication" as a Cultural Category in Some American Speech. Communication Monographs, 48, 30317.

King, Y. A., \& Myers, J. T. (1977). Shame as An Incomplete Conception of Chinese culture: A study of face. Hong Kong: The Chinese University of Hong Kong, Social Research Centre.

Leeds-Hurwitz, W. (1995). Social Approaches to Communication. New York: The Guilford Press. 
Ma, R. (1992). The Role of Unofficial Intermediaries in Interpersonal Conflicts in the Chinese Communication Quarterly, 40(3), 269-278.

Monaghan, L, \& Goodman, J. (Eds.) (2006). A Cultural Approach to Interpersonal Communication: Essential Readings. Malden, MA: Blackwell Publishing.

Philipsen, G. (1992). Speaking Culturally: Explorations in Social Communication. Albany, NY: SUNY Press.

Schneider, D. M. (1968). American kinship: A Cultural Account. Englewood Cliffs, N.J.: Prentice-Hall.

Scollon, R., \& Scollon, S. W. (1994). Face parameters in East-West Discourse. In S. Ting-Toomey (Ed.), The Challenge of Facework: Cross-cultural and Interpersonal Issues (pp. 133-157). Albany, NY: SUNY Press.

Stewart, J. (2002) (Ed.), Bridges Not Walls: A book on Interpersonal Communication (8th). New York: McGraw Hill.

Ting-Toomey, S. (1985). Toward a Theory of Conflict and Culture. In W.B. Gudykunst, L.P.Stewart, \& S. Ting-Toomey (Eds.), Communication, Culture, and Organizational Processes (pp. 71-86). Beverly Hills, CA: Sage.

Ting-Toomey, S., \& Oetzel, J. (2002). Conflict Style Differences between Individualists and Collectivists. Communication Monographs, 69, 67-87.

Tracy, K. (2002). Everyday Talk: Building and Reflecting Identities. New York: The Guilfor Press.

Yum, J. O. (1988). The Impact of Confucianism on Interpersonal Relationships and Communication Patterns in East Asia. Communication Monographs, 55, 374-88.

Zhang, Q. (2007). Family Communication Patterns and Conflict Styles in Chinese Parent-child Relationships. Communication Quarterly, 55(1), 113-128.

Zhong, M., Myers, S. A., \& Buerkel, R. A. (2004). Communication and Intergenerational Differences between Chinese Fathers and Sons. Journal of Intercultural Communication Research, 33(1), 1527.

当年曾是父母的骄傲清华毕业生回乡卖炒粉 [Once parents' honor, a Qinghua University Graduate now sells noodles back 
Ogirisi: a new journal of African studies Vol. 8, 2011

home]. (2007, March 30). 羊城晚报 [Yang Cheng Evening News].

Retrieved March 30, 2007, from http://wenxuecity.com 